\title{
Analysis on Operating Method in Travel System of Wheel Loader
}

\author{
Zhenbao Wang ${ }^{a}$, Sicheng Qin ${ }^{b}$ \\ School of Jilin University, Changchun 130022, China. \\ awangzhenbao1989@126.com, bqsc925@hotmail.com
}

Keywords: Wheel loader, Operating method, Resistance, Relevant feature.

\begin{abstract}
The operating performances in transportation distance and method of wheel loader have great influence to the efficiency and energy consumption of engineering works. In order to improve economic rationality and scientific of engineering projects effectively, V-shaped shovel cycling conditions of the 50 type wheel loader was tested. The basic energy consumption law of travel system in the process of operation was studied, and velocity, tractive force, running resistances and operating method of the loader cycling test condition were analyzed.
\end{abstract}

\section{Introduction}

Wheel loader is easy to operate, but shovel transport distance and operating type will influence strongly on operating efficiency and operating economy as for performance under construction. The performance of loader has to be analyzed deeply so that scientificity and economy of loader during operating process can be enhanced [1].

At present, research on performance of loader mainly concentrates on two aspects: the first one is about research on the hydraulic system load and spading resistance. The spading trajectory can be optimized depending on this and energy consumption can be decreased during the performance process [2]. The second one is about research on driving system loading spectrum [3]. But now overall description about the basic law of power demand of loader walking system is scarce. Power demand at performance terminal embodies the most basic power demand law of loader, and only based on this the performance of loader can be arranged reasonably. Based on analysis of testing data, this paper studied the power demand law of loader walking system performance terminal.

\section{Testing and Data Pre-Processing}

\subsection{Test Conditions.}

The test was conducted with a certain good work performance ZL50 loader, which can use V shovel loader operating type. The test includes 60 cycle operations. In order to eliminate effects that are caused by different operating habits, the test was conducted by 3 different operators and lasted for 40 seconds for a complete cycle operation. The shovel loading material is gravel. Bucket full rate is beyond $95 \%$ for each time. The test site is concrete pavement.

\subsection{Data Collection.}

There are 4 testing items: Selecting the gearbox output shaft to arrange torque sensor and testing torque from gearbox output shaft to the front and rear axles; The input speed of gearbox can be measured at a speed sensor that is arranged at the first transmission gear of gearbox; recording variation of gears by gears' pressure signals of gearboxes; measuring loader' speed by GPS-RTK method. Considering that the working environment of loader are bad, so wireless telemetry method will be used to test the torque signal and cable test method will be used to test revolving speed signal. The network data collector who's collecting frequency is $100 \mathrm{HZ}$ to do real-time synchronous measurement. The data can be recorded and analyzed by measuring computer system.

\subsection{Data Pre-Processing.}

The test system exists inevitable interference because bad working environment. In order to analyze and process signals conveniently, the first step is to do filtering denoising and eliminate trend terms. 
Next the method that the amplitude threshold and the gradient threshold are combined will be used to eliminate abnormal peak point of testing data [4]. Every operating cycle can be divided into 5 working phases, which include no-load forward, spading, retreat, and forward lift unloading and no-load backward. It has been verified that revolving speed and torque signals at every phase are stable and ergodic.

\section{Data Processing and Analysis}

The performance of loader is very disciplinary and cyclical, so the energy consumption and distributing rule of loader can be studied according to a certain operating cycle. The law of power demand of loader walking system embodies mainly in traction force, speed, driving resistance and performance at each working period. Performance characteristics include shovel transport distance and time distribution [5].

\subsection{Data Collection.}

The traction calculating formula of loader is following:

$$
F_{k}=\frac{\left(T_{1}+T_{2}\right) i_{q} i_{l} \eta_{g} \eta_{l}}{r}
$$

In Eq.1: $T_{1}$ refers to front drive axle output torque; $T_{2}$ refers to back drive axle output torque; $i_{q}$ refers to driving ratio of main drive; $i_{l}$ refers to driving ratio of hub reduction gear; $\eta_{g}$ refers to transmission efficiency of main drive; $\eta_{l}$ refers to transmission efficiency of hub reduction gear; $r$ refers to tire radius .

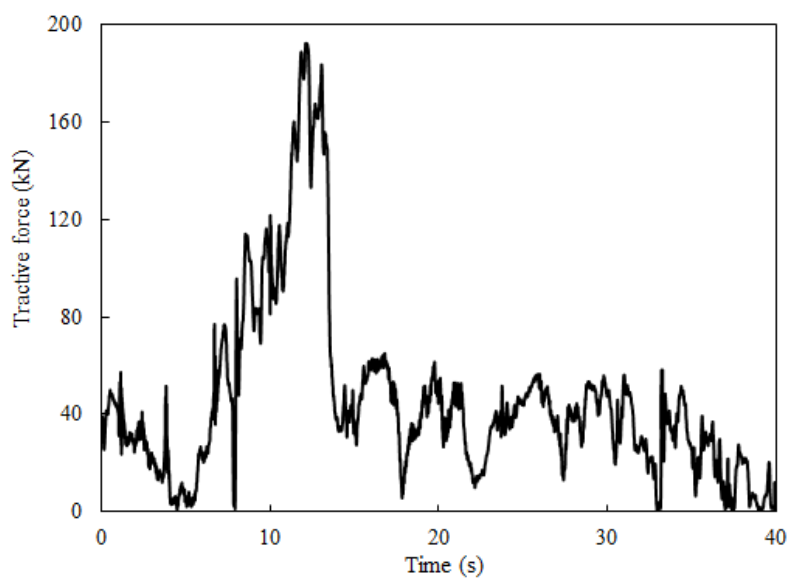

Fig. 1 Tractive force

The Fig. 1 shows that the average traction at spading working segments is twice more than others' during a $\mathrm{V}$ shovel spading operation cycle of loader. Traction variation rules at other operating periods are close and the difference value of maximum traction is much smaller.

It is too difficult to measure the speed of loader directly because complicated and varied working environment. Meanwhile, measurement accuracy is low, so the speed of loader has to be calculated by gearbox input speed signals:

$v=\frac{2 \pi n r S}{i_{g} i_{q} i_{l}}$

As for wheel type construction machinery (tire pressure is within 0.2 0.3 $\mathrm{MPa}$ ) [6]:

$$
S=0.1 \frac{F_{k}}{G_{\varphi}}+(5.48 \sim 9.25)\left(\frac{F_{k}}{G_{\varphi}}\right)^{8}
$$

In Eq.3: $n$ refers to the turbine speed; $S$ refers to wheel slip rate; $i_{g}$ refers to driving ratio of gearbox; $G_{\varphi}$ refers to adhesive weight. 


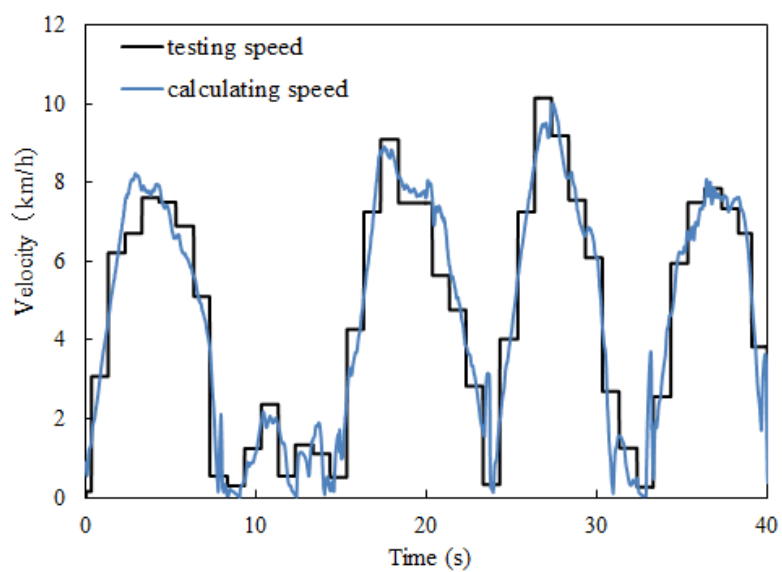

Fig. 2 Velocity

Fig. 2 shows that the speed of loader varies periodically. This periodicity plays a role that can divide working phases of cycling operating mode and judge the function of gear variation; during the test, besides spading period of loader belongs to the first block, other working periods belong to the second block. Because the test site is flat, the variation of wheel slip rate is small, so difference value between calculating speed and testing speed is also small.

When the vehicle is in the procession, it will bear the force of the traction drive and driving resistance. The relation between the two is following:

$$
F_{k}=\sum F
$$

In Eq.5: $\sum F$ refers to the sum of all the driving resistance.

Driving resistance of loader includes: rolling resistance, air resistance, grade resistance, inertial resistance, insertion resistance and so on [7]. The size of the rolling resistance is proportional to the vehicle weight. The structure of pneumatic in tires and road conditions also will influence the rolling resistance:

$$
F_{f}=G f
$$

In Eq.6: $G$ refers to total weight of loader; $f$ refers to the coefficient of rolling resistance of tires. Varied range of coefficient of rolling resistance at a specific site is small, so the coefficient of rolling resistance of concrete pavement is $f=0.023$ according to one table.

When the vehicle is in the procession, it will bear air resistance, which is related to appearance of vehicles, relative speed of air, air density and other factors:

$$
F_{w}=\frac{C A v^{2}}{21.15}
$$

In Eq.7: $C$ refers to coefficient of air resistance that is 0.7; $A$ refers to windward area of loader. The maximum air resistance of loader under low air speed is:

$$
F_{w-\max }=\frac{6.1 \times 0.7 \times 38.5^{2}}{21.15 \times 3.6^{2}}=23.09 \mathrm{~N}
$$

According to the above calculating results, we can know that the air resistance of the loader is much smaller than other resistances during the operating process. And meanwhile, the air resistance and grade resistance can be ignored because of the small grade of the test site.

Loader will bear insertion resistance under spading process. With the increase of bucket's inserting depth, the insertion resistance will gradually increase. Bucket inserting length depends on the maximum traction of vehicles:

$$
F_{x}=9.8 K_{1} K_{2} K_{3} K_{4} B L^{1.25}
$$

In Eq.8: $K_{1}$ refers to the coefficient of loose degree and fragmentation of materials; $K_{2}$ refers to the coefficient of nature of materials; $K_{3}$ refers to the coefficient of height of material piles; $K_{4}$ refers to the coefficient of influence of bucket shape; $B$ refers to bucket width; $L$ refers to the depth that buckets dig into material piles. 
The speed of loader at each working period of cycling operating mode includes acceleration, constant speed and deceleration-stopping. During this process, the loader will bear inertial resistance:

$F_{a}=F_{k}-F_{f}-F_{x}$

All the driving resistances of loader under the same operating cycle are shown in Fig. 3.

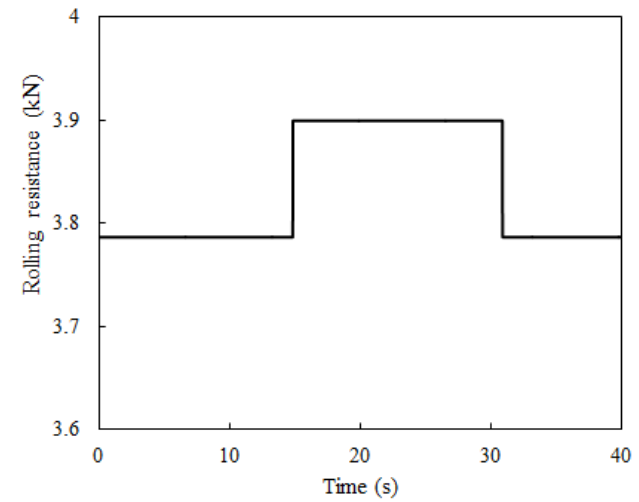

a. Rolling resistance

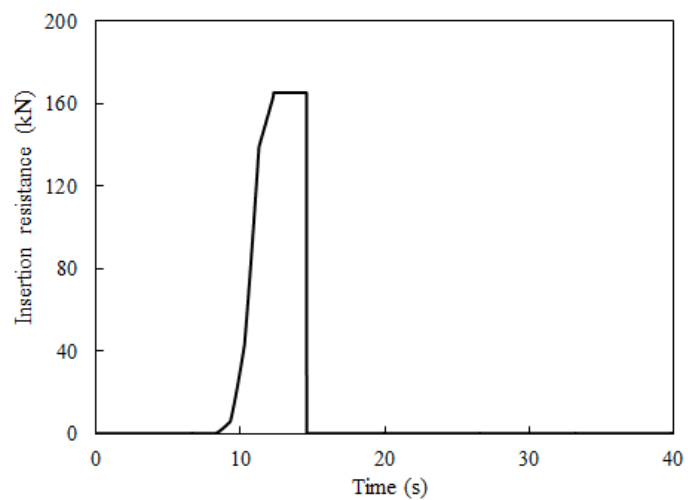

b. Insertion resistance

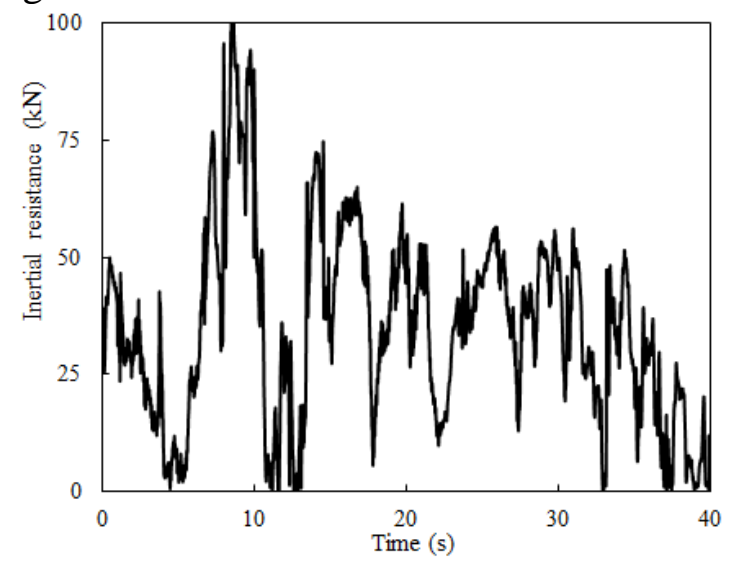

c. Inertial resistance

Fig. 3 Driving resistances

The Fig. 3 can show that besides loader will bear insertion resistance at spading phase, inertial resistance will expend more than $90 \%$ of traction at other working phases.

\subsection{Performance at Working Periods.}

Data of characteristics of performance can be extracted according to all divided isolated working period. The result is shown in table 1 .

Table 1. Feature data of wheel loader work cycle

\begin{tabular}{cccccc}
\hline State & Advance & $\begin{array}{c}\text { Shovel } \\
\text { loading }\end{array}$ & Retreat & $\begin{array}{c}\text { Advance lifting } \\
\text { discharge }\end{array}$ & $\begin{array}{c}\text { No-load } \\
\text { backward }\end{array}$ \\
\hline Time[s] & 8.2 & 6.4 & 9.3 & 8.9 & 7.2 \\
Distance[m] & 12.0 & 1.4 & 13.4 & 12.7 & 12.7
\end{tabular}

Acceleration speed of vehicles during loader' operating cycle can directly determine inertial resistance of vehicles:

$$
F_{a}=\delta \frac{G}{g} a
$$

In the Eq.11: $a$ refers to acceleration speed of loader; $\delta$ refers to the transforming coefficient of rotating mass.

The calculating formula of transforming coefficient of rotating mass is following:

$$
\delta=1+\frac{\sum I_{w}}{m_{a} r^{2}}+\frac{I_{f} i_{g}^{2} i_{q}^{2} \eta_{z}}{m_{a} r^{2}}
$$


In Eq.12: $I_{w}$ refers to inertia of wheel rotating; $m_{a}$ refers to total mass of loader; $I_{f}$ refers to the sum of inertia among the engine flywheel, hydraulic torque converter pump impeller and turbines. $\eta_{z}$ refers to total transmission efficiency of transmission system. Figure 4 shows the comparative result between calculating results of inertial resistance and testing data.

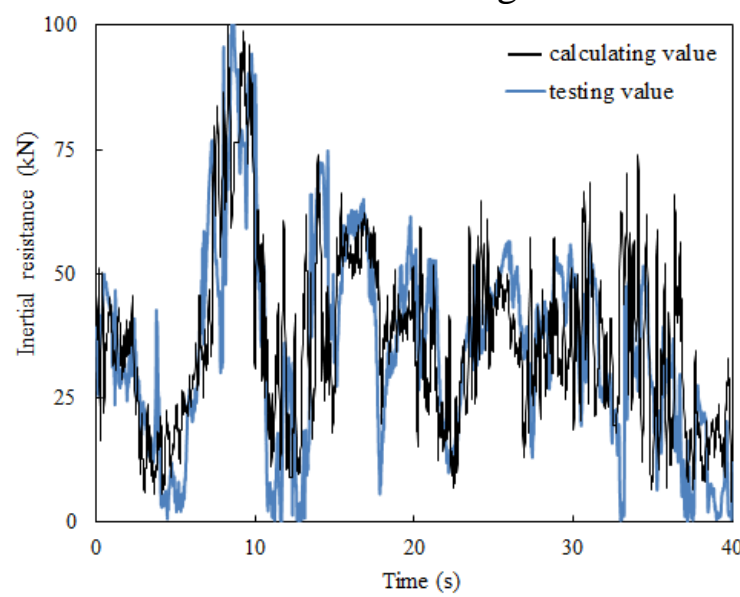

Fig. 4 Calculated results and experimental values of inertial resistance

According to Fig. 4, it shows that difference value between calculating result of inertial resistance and testing value is small, and also it can satisfy engineering calculation requirement. Meanwhile, it can suggest that performance of loader at working period play a crucial role to energy consumption of a complete operating mode.

\section{Summary}

The analysis of the law of power demand of loader walking system can provide the necessary data support for energy saving mechanism research and simulation research.

\section{References}

[1]. Z.H. Sun. The Application research on operating method of construction loader [J]. Agricultural Equipment \& Vehicle Engineering, (2008) No. 11, p. 55-59.

[2]. J. Gong, Y.X. Cui. Track planning for a wheel loader in a digging [J]. Journal of Mechanical Engineering, Vol. 45 (2005) No. 7, p. 29-34.

[3]. J. Gong, J.F. Bao, G.C. Yi, et al. Trajectory-following control for manipulator of wheel loaders based on computed torque [J]. Journal of Mechanical Engineering, Vol. 46 (2010) No. 13, p. 141-146.

[4]. Y.S. Zhang, G.Q. Wang, J.X. Wang, et al. Compilation method of power-train load spectrum of engineering vehicle [J]. Transactions of the Chinese Society of Agricultural Engineering, Vol. 27 (2011) No. 4, p. 179-183.

[5]. Y.C. Liu, L. Chang, L. Sun. A method of compiling load spectrum on wheel loader transmission [J]. China Mechanical Engineering, Vol. 23 (2012) No. 12, p. 1412-1416.

[6]. Bengtsson. A, Rychlik. I. Uncertainty in fatigue life prediction of structures subject to Gaussian loads [J]. Probabilistic Engineering Mechanics, Vol. 24 (2009) No. 2, p. 224-235.

[7]. Klemenc. J, Fajdiga. M. Improved modelling of the loading spectra using a mixture model approach [J]. International Journal of Fatigue, Vol. 30(2008) No. 7, p. 1298-1313. 